\title{
Isolation and Characterization of a MADS-box Gene cDNA, PnMADS1, That is Expressed in Both Vegetative and Floral Meristems of Pharbitis nil
}

\author{
Michiyuki ONO*1), Kimiyo SAGE-ONO**, Wakako MARUYAMA**, Michihiro KAWAKAMI**, \\ Masayasu INOUE* and Hiroshi KAMADA** \\ *Biotechnology Institute, Akita Prefectural University, Ohgata, Akita, 010-0444 Japan \\ **Institute of Biological Sciences, University of Tsukuba, Tsukuba, Ibaraki, 305-8572 Japan \\ I) Corresponding author E-mail address:
}

Received 28 January 2000; accepted 10 February 2000

\begin{abstract}
A novel cDNA corresponding to a gene designated PnMADS1 and encoding a MADS- box protein was isolated from the short-day plant Pharbitis nil (Japanese morning glory) cv. Violet. Phylogenetic analysis of the amino acid sequence encoded by PnMADS1 indicated that PnMADS1 does not belong to any of the major sub-groups of MADS - box proteins. The protein exhibited some similarity to proteins in the so-called 'orphan group' of unclassified MADS-box proteins that are mainly expressed in vegetative organs. The most similar MADS - box genes were AGL24 and StMADS16 (53.2\% and 52.3\% identity at the deduced amino-acid level, respectively). We obtained evidence that PnMADS1 mRNA accumulates in both vegetative and floral meristems but not in any other vegetative organs. Our results indicate that PnMADS1 is a novel MADS-box protein in terms of both structure and pattern of expression.
\end{abstract}

Key words: Floral induction-Flower development - MADS box-Pharbitis nil-Vegetative development Footnote: The nucleotide sequence reported in this paper has been submitted to the EMBL, GenBank and DDBJ Nucleotide Sequence Databases under accession number D84512.

\section{Introduction}

Numerous MADS-box genes have been found in a wide variety of eukaryotes, from yeast to plants and man (Shore and Sharrocks, 1995; Hasebe et al., 1988). Each MADS-box protein contains a DNAbinding domain, known as a MADS box, which consists of 57 strongly conserved amino acids (Schwarz-Sommer et al., 1990; Ma et al., 1991). MADS-box proteins play key roles as transcription factors. In plants, the control of flower development by floral homeotic genes, which include MADSbox genes, has been studied extensively in Arabidopsis and Antirrhinum (Coen and Meyerowitz, 1991; Yanofsky, 1995). Several MADS-box genes have been isolated from various plant species and characterized, and some of them have been shown to be expressed during vegetative development (Ma et al., 1991; Pnueli et al., 1991; Mandel et al., 1994; Heard and Dunn, 1995; Rounsley et al., 1995; Zachgo et al., 1997).

Pharbitis nil cv. Violet is a short-day plant that has been used as a model plant for studies of photoperiodic induction of flowering (Imamura, 1967; Vince-Prue and Gressel, 1985). Seedlings of $P$. nil cv. Violet grown under continuous light (i.e., under ideal non-inductive conditions) are induced to flower by a single 16 - $\mathrm{h}$ exposure to continuous darkness. Thus, almost absolute states of vegetative growth and reproductive growth can easily be established (Imamura, 1967; Vince-Prue and Gressel, 1985). We postulated that this feature would be useful for studies of MADS-box genes that are expressed in apical meristems during vegetative growth, as well as during reproductive growth. Analysis of such genes should provide fundamental information about the induction and development of flowers.

In this study, we isolated a novel MADS-box gene from Pharbitis, which is expressed in vegetative and reproductive apical meristems. This gene, PnMADS1, seems to be unique in terms both of amino acid sequence and pattern of expression. 


\section{Materials and Methods}

\subsection{Plant materials}

Seeds of Pharbitis nil Choisy cv. Violet (obtained from Marutane Co., Kyoto, Japan) were soaked in concentrated sulfuric acid for $30 \mathrm{~min}$, with occasional stirring, and then rinsed in running tap water for $1 \mathrm{~h}$. The seeds were then soaked in a large volume of distilled water for $16 \mathrm{~h}$ and sown on wet vermiculite for germination. Germination and growth of seedlings were allowed to proceed at 25 $\pm 1^{\circ} \mathrm{C}$ with continuous illumination from coolwhite fluorescent lamps (FLR80H-WA; Matsushita Electronics Co., Tokyo, Japan; $13.6 \mathrm{~W} \mathrm{~m}^{-2}$ ) in cultivation chambers (CU-350; Tomy Seiko Co., Tokyo, Japan). When the cotyledons had extended maximally (6 days after treatment with sulfuric acid), photoperiodic treatments were applied (SageOno et al., 1998). The seedlings were divided into two groups and subjected to SD treatment $(16 \mathrm{~h}$ of continuous darkness, namely, flower-inductive conditions) or to LD treatment (continuous light, namely, non-inductive conditions). Apical buds, including flower buds, young leaves and stems, were excised 2, 3, 4, 5, 7 and 10 days after induction of flowers, frozen in liquid nitrogen and stored at $-80^{\circ} \mathrm{C}$.

\subsection{Construction and screening of a cDNA library}

Total RNA was isolated from each sample as described by Ozeki et al., (1990). Poly $\left(\mathrm{A}^{+}\right)$RNA was isolated by chromatography on oligo(dT)-cellulose (Amersham-Pharmacia, Tokyo), as described originally by Aviv and Leder (1972). A cDNA library was constructed from the poly $\left(\mathrm{A}^{+}\right) \mathrm{RNA}$ of apical buds of $P$. nil, 2, 3, 4, 5, 7 and 10 days after induction of flowering, using commercial kits for synthesis and cloning of cDNA (AmershamPharmacia) in accordance with the instructions from the manufacturer. Screening of plaques and preparation of phage DNA were also performed according to the instructions from Amersham-Pharmacia. The molecular probe used for screening the cDNA library was a ${ }^{32} \mathrm{P}$-labeled fragment of DNA encoding a MADS-box domain. For preparation of the probe, two oligonucleotide primers were synthesized and used for amplification by PCR of the DNA fragment that encoded the MADS-box domain of the AGAMOUS (AG) gene of Arabidopsis (Yanofsky et al., 1990). One was identical to nucleotides (nt) 1 through 27 and the other was complementary to nt 149 through 175 of the published sequence of $A G$ cDNA (Yanofsky et al., 1990). A genomic clone of Arabidopsis DNA con- taining the $A G$ gene (cloned, sequenced and generously donated by Dr. J. Imamura, Plantech Research Institute, Yokohama, Japan) was used as template for amplification. During the screening of 200,000 recombinant phages in the $P$. nil library, we isolated several positive plaques. The insert DNAs were subcloned into the $E c o$ RI site of pBluescript IIKS+ (Stratagene, La Jolla, CA, U.S.A.) and sequenced. One of the clones that we characterized was designated PnMADS1 (for the gene for MADS1 of Pharbitis nil ). Because the cDNA lacked an initiation codon and the 5' non-coding sequence, the full-length cDNA was prepared with a 5'RACE kit (Clontech Lab. Inc., Tokyo, Japan) using specific primers (Frohman et al., 1998).

\subsection{Sequencing and analysis of DNA}

The nucleotide sequence of PnMADS1 cDNA was determined with fluorescent primers and an automated DNA sequencer (model 373A; Applied Biosystems, Chiba, Japan). Nucleotide and amino acid sequences were analyzed with GENETYXMAC software (Software Development Co. Ltd., Tokyo, Japan). Databases were searched with TFASTA 3.08, TFASTX 3.09 and TBLASTN 2.0.7 (DNA Data Bank of Japan, Mishima, Shizuoka, Japan; Altschul et al., 1997; Pearson and Lipman, 1988). The phylogenetic tree was obtained with the neighbor-joining method (Saitou and Nei, 1987). The amino acid sequences of MADS-box proteins were aligned by using the Clustal $\mathrm{X}$ program (Thompson et al., 1997) and then were revised manually. Bootstrap values were also calculated using the same program. The resulting phenogram was drawn with Niplot program (M. Gouy, Universite Claude Bernard-Lyon 1, Lyon, France). Nodes with $<50 \%$ bootstrap support were collapsed as described previously by Purugganan et al., (1995).

\subsection{Southern hybridization}

We prepared a DNA fragment specific for PnMADS1 as a molecular probe. To avoid crosshybridization with other MADS-box genes, digestion at the PstI site located 279 bp from the 5' end of PnMADS1 cDNA was performed to remove the MADS-coding sequence. The rest of the cDNA (the 630-bp PstI fragment) was used for all hybridization experiments. Genomic DNA was isolated from apical buds with small leaves of $P$. nil as described by Rogers and Bendich, (1985). It was digested separately with EcoRI, BamHI, HindIII and XhoI. Digested DNA was fractionated by electrophoresis on an agarose gel and bands of DNA were transferred to a nylon membrane filter (Biodyne B; Nihon Pall, Ltd., Tokyo, Japan). The DNA on the 
filter was allowed to hybridize with the ${ }^{32} \mathrm{P}$-labeled 630-bp PstI fragment of PnMADS1 cDNA in hybridization buffer that contained $6 x$ SSPE $(1 x$ SSPE is $0.18 \mathrm{M} \mathrm{NaCl}, 0.01 \mathrm{M}$ sodium phosphate, and $1 \mathrm{mM} \mathrm{Na}{ }_{2}$ EDTA, pH 7.7), 5x Denhardt's solution ( $1 \mathrm{x}$ Denhardt's solution is $0.02 \%$ Ficoll, $0.02 \%$ polyvinylpyrrolidone, and $0.02 \%$ bovine serum albumin) plus $0.5 \%$ SDS and $150 \mu \mathrm{g} \mathrm{m}^{-1}$ salmon sperm DNA at $65^{\circ} \mathrm{C}$ for $16 \mathrm{~h}$. The filter was washed twice with $2 \times$ SSPE plus $0.1 \%$ SDS for $5 \mathrm{~min}$ at room temperature and then twice with $0.1 \%$ SSPE plus $0.1 \%$ SDS for $30 \mathrm{~min}$ at $65^{\circ} \mathrm{C}$ (high-stringency conditions) (Sage-Ono et al., 1998). For visualization of bands on the filter, we used a bioimaging analyzer with an imaging plate (BAS2000; Fuji Photo Film Co., Ltd., Tokyo, Japan).

\subsection{Northern hybridization}

Total RNA $(20 \mu \mathrm{g})$ was fractionated by electrophoresis on a formaldehyde-agarose gel and then bands of RNA were transferred to a nylon membrane filter (Biodyne B). The RNA on the filter was allowed to hybridize with the ${ }^{32} \mathrm{P}$-labeled $630-\mathrm{bp}$ PstI fragment of PnMADS1 cDNA. The conditions for hybridization, washing and analysis were as described previously by Sage-Ono et al., (1998).

\subsection{Reverse transcription-PCR}

Total RNA was prepared from various organs as described above and was then treated with RNasefree DNaseI (Promega) to eliminate contaminating fragments of genomic DNA. Purified total RNA (1 $\mu \mathrm{g})$ was reverse transcribed with an oligo(dT) primer. The reaction mixture for reverse transcription (total volume $20 \mu \mathrm{l}$ ) contained $10 \mathrm{mM}$ Tris$\mathrm{HCl}(\mathrm{pH} 8.3), 50 \mathrm{mM} \mathrm{KCl}, 5 \mathrm{mM} \mathrm{MgCl} 2,2.5 \mu \mathrm{M}$ oligo $(\mathrm{dT})_{36}$ primer, $1 \mathrm{mM}$ dNTPs and $20 \mathrm{U}$ of RNase inhibitor (Takara, Tokyo), and reactions were performed as follows. The mixture was heated at $65{ }^{\circ} \mathrm{C}$ for $5 \mathrm{~min}$ and then at $37{ }^{\circ} \mathrm{C}$ for $10 \mathrm{~min}$, after which $5 \mathrm{U}$ of AMV reverse transcriptase XL (Life Sciences Inc., St. Petersburg, FL, U.S.A.) were added. The mixture was heated at $42{ }^{\circ} \mathrm{C}$ for $60 \mathrm{~min}$ and at $95^{\circ} \mathrm{C}$ for $5 \mathrm{~min}$, and then it was stored at -20 ${ }^{\circ} \mathrm{C}$ prior to PCR. One or two microliters of this mixture were used as the source of template for PCR in a reaction mixture that contained the PnMADS1 - specific primers 5' - CAGCAGTTGGAGAGGTC-3' and 5'-AACTTCATAATAATCTTGTG-3'. The solution for PCR (total volume $50 \mu \mathrm{l}$ ) contained $10 \mathrm{mM}$ Tris- $\mathrm{HCl}(\mathrm{pH} 8.3), 50 \mathrm{mM} \mathrm{KCl}$, $1.5 \mathrm{mM} \mathrm{MgCl}_{2}, 0.001 \%(\mathrm{v} / \mathrm{v})$ gelatin, $0.2 \mu \mathrm{M}$ PnMADS1-specific primers, $200 \mu \mathrm{M}$ dNTPs, and $1.25 \mathrm{U}$ of AmpliTaq ${ }^{\mathrm{TM}}$ DNA polymerase (Perkin Elmer Cetus, Norwalk, CT, U.S.A.). PCR involved
30 to 40 cycles of incubation at $94^{\circ} \mathrm{C}$ for $1 \mathrm{~min}, 54^{\circ} \mathrm{C}$ for $1 \mathrm{~min}$, and $72{ }^{\circ} \mathrm{C}$ for $2 \mathrm{~min}$. Aliquots of duplicate reaction mixtures after PCR were subjected to electrophoresis on a 5\% polyacrylamide gel to separate amplified cDNAs. Then cDNAs were blotted onto a nylon membrane filter, allowed to hybridize with a ${ }^{32} \mathrm{P}$-labeled specific probe and visualized by exposure to a $X$-ray film. The expected length of the product of PCR was $285 \mathrm{bp}$ and the products corresponded to 410 to $695 \mathrm{bp}$ of PnMADS1 cDNA. To confirm the quality of the original samples of RNA and to serve as a positive control, the same cDNA templates were used for PCR with primers for the amplification of actin cDNA, namely, 5' - TCCATAATGAAGTGTGATGT-3' and 5'-GGACCTGACTCGTCATACTC-3'. The expected length of the amplified fragment of actin cDNA was $259 \mathrm{bp}$ and the products corresponded to PnACT1 (accession number in DDBJ, D78204), PnACT3-1 (D78205), and PnACT3-3 (D78206). To avoid saturation conditions, we determined the appropriate number of cycles for each PCR.

\subsection{In situ hybridization}

Apical buds of $5 \mathrm{~mm}$ in length were fixed in a solution of $10 \%$ formaldehyde, 5\% acetic acid and $50 \%$ ethanol, embedded in wax (Paraplast plus; Oxford Labware, St. Louis, MO, U.S.A.), and sectioned. The 630-bp PstI fragment of PnMADS1 cDNA was subcloned into pBluescript IIKS+ to provide templates for $\mathrm{T} 7$ polymerase and $\mathrm{T} 3$ polymerase for the synthesis of sense and antisense RNA probes. Probes for in situ hybridization were labeled with digoxigenin-11-rUTP with a nucleic acid-labeling kit from Boehringer Mannheim Biochemica (Mannheim, Germany). In situ hybridization and immunological detection of the hybridized probe were performed as described in the instruction from Boehringer Mannheim Biochemica.

\section{Results}

\subsection{Nucleotide sequence of PnMADS1 cDNA and the deduced amino acid sequence}

PnMADS1 cDNA was 906 bp long and contained a 705-bp open reading frame that encoded a putative protein of 234 amino acids, as well as a 34-bp 5 ' non-coding region and a 167-bp 3' non-coding region. The cDNA appeared to be nearly fulllength because it included a region that encoded a complete MADS-box domain, with a conserved initiation codon and a polyadenylated tail. The deduced amino acid sequence was typical of MADS - box proteins from plants. The MADS-box domain was followed by an intermediate domain, a keratin- 
like domain, and a carboxy-terminal domain (Fig. 1; Ma et al., 1991).

\subsection{Similarity to other proteins at the amino acid level}

The amino acid sequence deduced from PnMADS1 cDNA was used in a search for homologous proteins as described in Materials and Methods. Homology scores were relatively low but the results of all searches were consistent (data not shown). Similar genes, listed in descending order of similarity, were AGL24, StMADS16, StMADS11, $A G L 17$ and $A G L 15$. The amino acid sequence of PnMADS1 exhibits $53.2 \%, 52.3 \%, 46.4 \%, 32.5 \%$ and $31.4 \%$ identical to AGL24, StMADS16, StMADS11, AGL17 and AGL15, respectively. StMADS11 and StMADS16 are MADS-box genes for vegetative proteins of potato that show some similarity to $A G L 15$ and $A G L 17$ (Carmona et al., 1998). $A G L 15$ and $A G L 17$ are members of the socalled 'orphan' group of MADS-box genes that do not belong in the well-characterized major family of MADS-box genes (Purugganan et al., 1995; Rounsley et al., 1995, Perry et al., 1996). Results of a phylogenetic analysis of amino acid sequences are presented in Fig. 2. The phylogenetic analysis by the neighbor-joining method indicated that PnMADS1 was distinct from other MADS-box proteins. We aligned the deduced amino acid sequence of PnMADS1 with those of AGL24, StMADS16, and StMADS11. As shown in Fig. 1, the MADS-box domain of PnMADS1 was somewhat different from those of the other somewhat similar proteins.

\subsection{Results of Southern and Northern analysis}

To determine the genomic organization of the PnMADS1 gene, we performed Southern hybridization using genomic DNA from $P$. nil that had been digested with EcoRI, Bam HI, HindIII and XhoI. The probe that we used was part of the cDNA, namely, a 630-bp PstI fragment that excluded the coding sequence of the strongly conserved MADS domain. Under stringent conditions, single hybridization bands were obtained (Fig. 3). Our results indicated that there was only one copy of the PnMADS1 gene in the genome of $P$. nil and confirmed that the probe was highly specific to the PnMADS1 gene. To characterize the temporal and organ-specific expression of the PnMADS1 gene, we performed

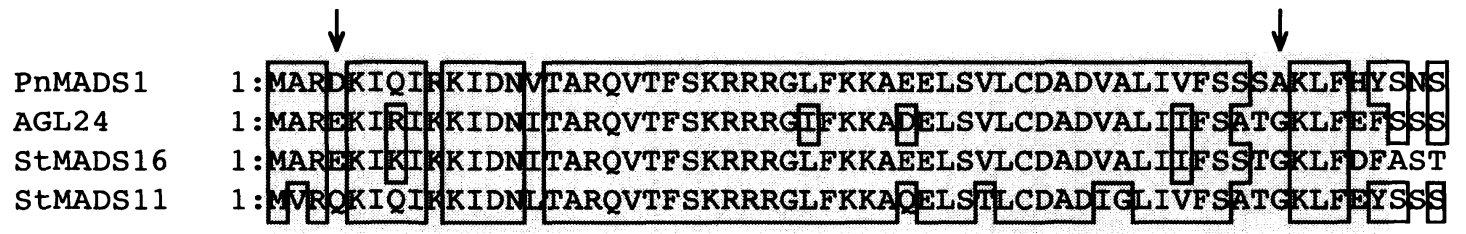

PNMADS1 $61:$ SMFE ILEKRNLHSKNIORMGLOPSVELQI-VENSNHSRSSKEIAEKTRR LRQMRVEELQE

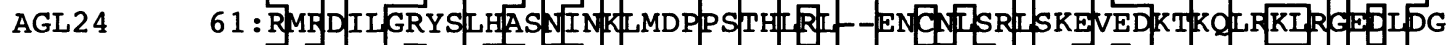

StMADS16 61:SMKDIIGRYKLOSASTEK-VDEPSLDLQI-ENSLNMRYSKQVRDKTRELRQMRGEELEG StMADS11 61:SMMQLIEKHKMOSERDSMDNPEQLHSSN LSE KKTEFAMISRDFYEKNRELROLHGEELGG

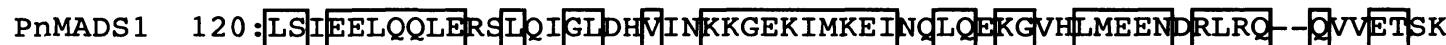
AGL24 119: LNLEELORLEKI L SGI SRVSEKKGECYNSOIF LLEKFGSEIVDENKRLRF--DKIET-

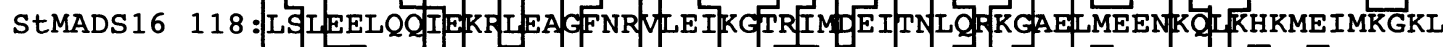

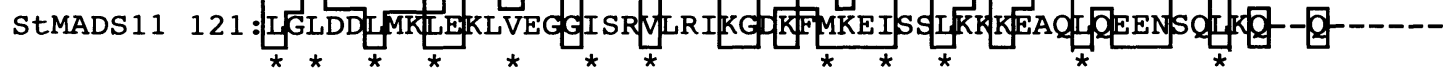

PNMADS1 178 : GQFS AVAARDSENLENE-EGGLSSESV-TNACKY1-P GTPQDYY EDCSDTSLKLGLPYTG

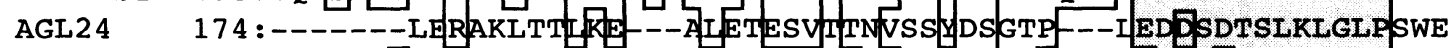
STMADS 16178 : PLLTDMTMEEGQSSESII-TTNNPDQDDSSNASLKLGGTT-AVEDDCSEISLKLGLPFS-

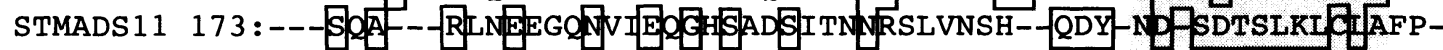

Fig. 1 Alignment of the amino acid sequence deduced from PnMADS1 cDNA with those of similar proteins. The amino acid sequences are given in the one-letter code and have been aligned, with the introduction of gaps (---), to maximize possible homology. Amino acids that are identical in PnMADS1 and other proteins are boxed. The MADSbox domain (residues 1 to 57) and the carboxy - terminal conserved motif are enclosed in shaded boxes. Asterisks indicate common hydrophobic amino acids (L, I, V, and M) in the region of the keratin-like domain. Asp at position 4 and Ala at position 52 are indicated by vertical arrows. 


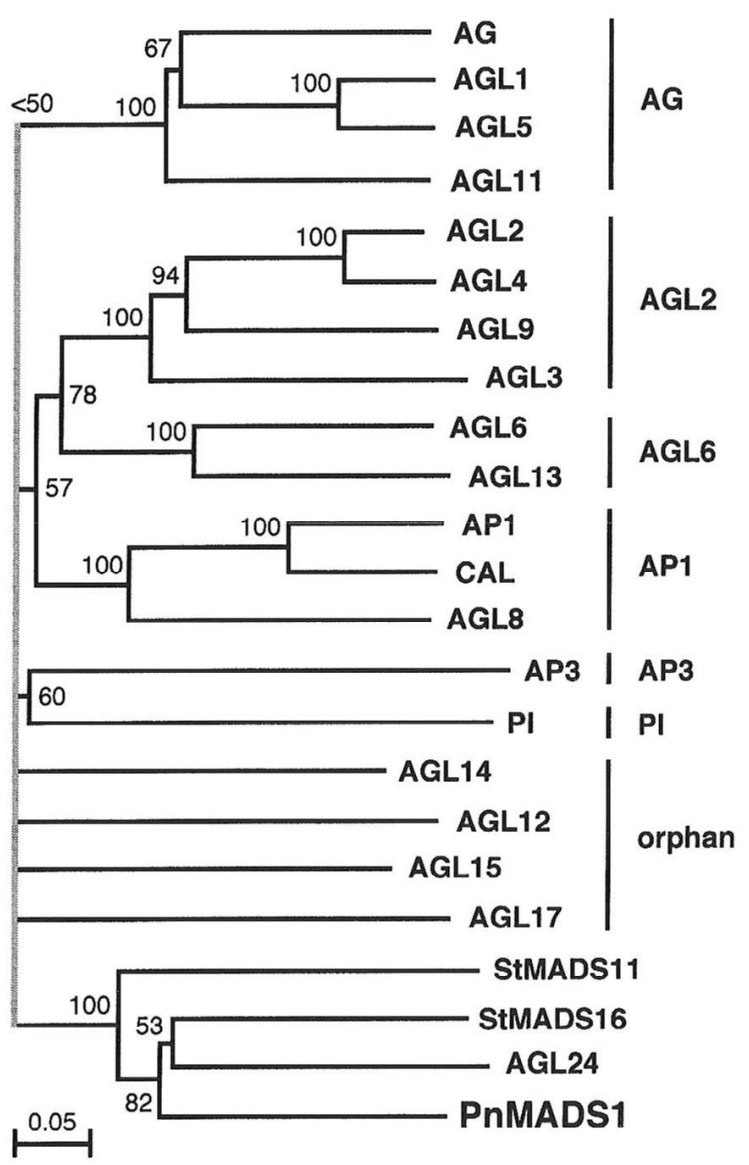

Fig. 2 A phylogenetic tree of plant MADS-box proteins based on the neighbor-joining method (Saito and Nei, 1987). PnMADS1, StMADS11, StMADS16 and characterized MADS-box proteins from Arabidopsis were presented. The horizontal branch length is proportional to the estimated number of amino acids substitutions per residue. (Bar=0.05 aa substitution per residue). Numbers at the branch points represent the bootstrap values for percentage of 1,000 replicate trees. This is an unrooted tree. Nodes with < $50 \%$ bootstrap support are collapsed. Sources of the amino acid sequences are as follows: AG (Genbank accession number P17839), AGL1 (P29381), AGL5 (P29385), AGL11 (AAC49080), AGL2 (P29382), AGL4 (P29384), AGL9 (O22456), AGL3 (P29383), AGL6 (P29386), AGL13 (AAC49081), AP1 (P35631), CAL (AAA64789), AGL8 (Q38876), AP3 (P35632), PI (P48007), AGL14 (CAB44326), AGL12 (AAC49085), AGL15 (Q38847), AGL17 (AAD15571), StMADS11 (AF008652), StMADS16 (AF008651) and AGL24 (AAC63139). The different gene groups are indicated on the right as described (Purugganan et al., 1995, Winter et al., 1999).

Northern blotting using total RNA extracted from apical buds and several vegetative organs of $P$. nil. Most samples of RNA did not yield any positive

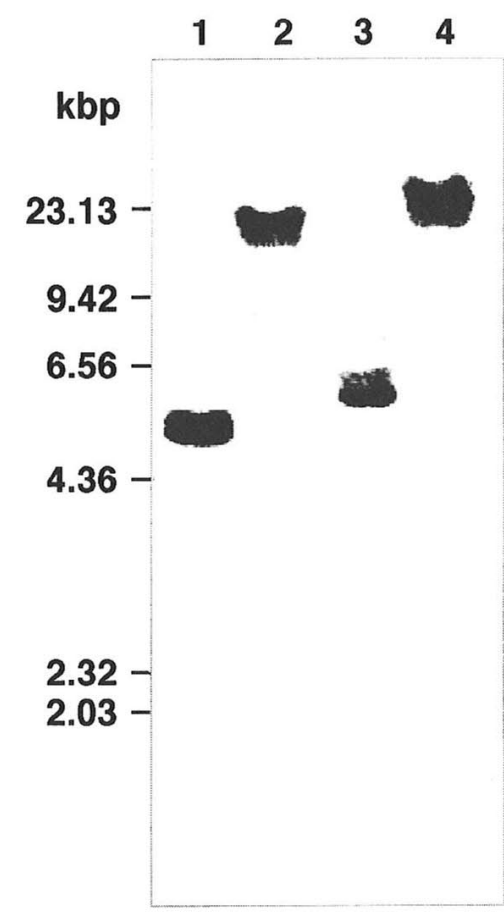

Fig. 3 Southern hybridization. Genomic DNA was prepared from Pharbitis nil cv. Violet. It was digested with EcoRI (lane 1), BamHI (lane 2), HindIII (lane 3) and XhoI (lane 4) and subjected to Southern hybridization. Results after washing under high-stringency conditions are shown. The probe used was the ${ }^{32} \mathrm{P}$-labeled $630-\mathrm{bp}$ PstI fragment of PnMADS1 cDNA. The mobilities of marker fragments are shown on the left in kilobase pairs (kbp).

signals (data not shown). However, weak signals were detected in the case of apical buds harvested 7 days and 10 days after short-day treatment (data not shown). The mRNAs were about $1.0 \mathrm{~kb}$ long, as estimated from the mobilities of rRNAs, which were used as size markers.

\subsection{Temporal and spatial expression of PnMADS1 $m R N A$}

Northern hybridization yielded only weak signals. Therefore, we applied a more sensitive method, namely, RT-PCR and detected PnMADS1 mRNA in apical buds at all stages of development (Fig. 4). The RNA isolated from other vegetative organs, namely, roots, stems, petioles and cotyledons, did not yield any signals. By contrast, positive controls with actin-specific primers consistently gave positive results. We also examined the spatial expression of PnMADS1 mRNA within apical buds at different developmental stages by in situ hybridization (Fig. 5). At the early stage of development of flower buds (3 days after floral induction), PnMADS1 was expressed in meristematic domains (Fig. 5A). This pattern of expression was indis- 


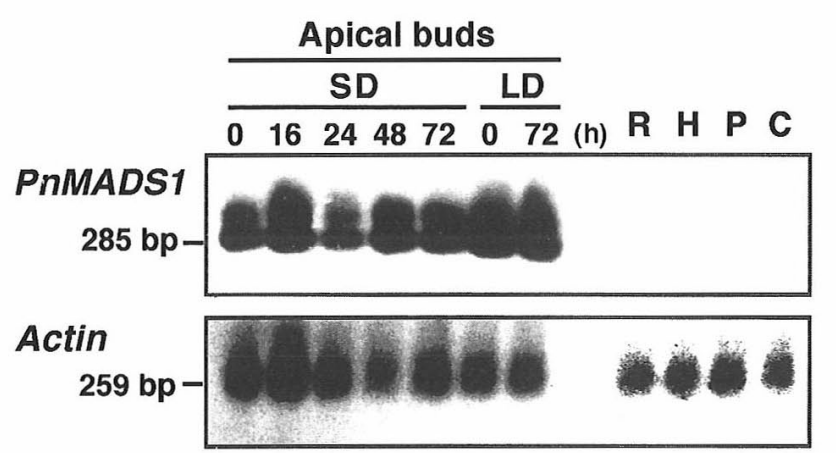

Fig. 4 Detection of PnMADS1 mRNA by RT-PCR.

Total RNA isolated from apical buds, roots (R), hypocotyls $(\mathrm{H})$, petioles $(\mathrm{P})$ and cotyledons (C) was analyzed for the presence of PnMADS1 mRNA by RT-PCR. Apical buds were harvested at the times indicated. Primers for RTPCR were specific for PnMADS1 and a gene for actin (as an internal control). Products of RTPCR were separated on a polyacrylamide gel, blotted onto a nylon membrane filter, allowed to hybridize with ${ }^{32} \mathrm{P}$-labeled specific probes, and exposed to $\mathrm{X}$-ray film for visualization. The lengths of products of PCR specific for PnMADS1 and actin were $285 \mathrm{bp}$ and $259 \mathrm{bp}$, respectively.

tinguishable from that in vegetative meristems (data not shown). In the floral meristems collected 7 days and 9 days after floral induction, we observed the preferential accumulation of PnMADS1 mRNA in petals, stamens and ovule primordia but not in sepal primordia (Figs. 5C and 5E). However, we detected no hybridization signals in floral buds collected 14 days after floral induction (Fig. 5F). No significant signal can be detected with the sense RNA (Fig. 5B and 5D).

\section{Discussion}

We isolated the cDNA for a MADS-box gene, PnMADS1, from a cDNA library constructed from apical buds of Pharbitis nil Choisy, cv. Violet after the induction of flowering. The amino acid sequence deduced from $P n M A D S 1$ did not correspond to that of any of the major and well-characterized MADS-box proteins. The most similar MADS-box gene was $A G L 24$, which exhibited $53.2 \%$ identity at the amino acid level. Such homology was lower than that between most MADS-box genes in any specific sub-family, which is usually more than $60 \%$ or $70 \%$. MADS-box proteins consist of several domains, namely, a MADS-box domain, an intermediate domain, a keratin-like domain and a carboxy-terminal domain (Ma et al., 1991, Purugganan et al., 1995). These domains in PnMADS1 were distinct, as shown in Fig. 1. The

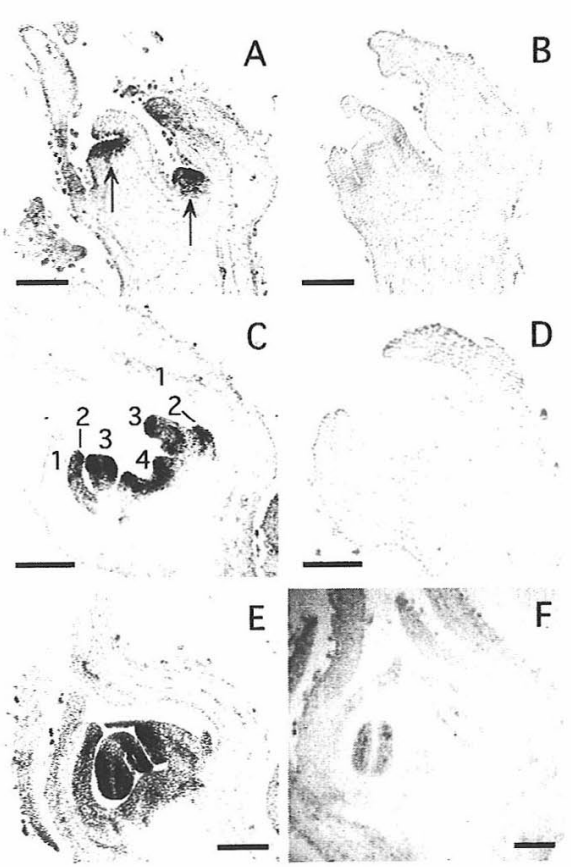

Fig. 5 In situ hybridization of PnMADS1 mRNA. Longitudinal sections of apical buds of Pharbitis were allowed to hybridize with digoxigeninlabeled antisense RNA (A, C, E, F) and sense RNA (B, D) derived from a PnMADS1-specific fragment of cDNA that excluded the coding sequence of the MADS-box domain. Apical buds were collected 3 days (A, B), 7 days (C, D), 9 days (E) and 14 days (F) after the short-day induction of flowering. Bars indicate $50 \mu \mathrm{m}$. Arrows in panel A indicate the meristematic domains. Numerals in panel $\mathrm{C}$ refer to the whorls that developed into sepals (1), petals (2), stamens (3) and carpels (4).

most significant differences were an Asp residue at position 4 and an Ala residue at position 52 in the MADS-box domain. MADS-box domains in the databases rarely contain these residues at these positions. The sequences of MADS-box domains within a single sub-family are usually much more homologous to each other. It appears that PnMADS1 might be related to $A G L 24$, StMADS16, and StMADS11 but it is clearly not a member of the same sub-family. This conclusion is supported by the results of studies of gene expression. However, there was a common motif in the carboxy-terminal sequence (Fig. 1). This motif is weakly conserved among members of the 'orphan group', namely, AGL15 and AGL17 (Carmona et al., 1998). The PnMADS1 gene appears to be the gene for a novel MADS-box protein that is similar to members of the orphan group of MADS-domain proteins (Purugganan et al., 1995).

We studied the temporal and spatial patterns of expression of the transcript of PnMADS1. Since only faint signals corresponding to PnMADS1 
mRNA were obtained by Northern hybridization, we used RT-PCR and in situ hybridization to detect transcripts. Expression of PnMADS1 was restricted to apical meristems during both vegetative and reproductive growth. Expression of PnMADS1 was detected in meristematic domains fated to form the inner three whorls, namely, petals, stamens, and ovary, of the flower (Fig. 5). The pattern of expression of PnMADS1 at the late stage of flower development is similar to that of TM5, a MADS-box gene in tomato (Pnueli et al., 1991) and to that of FBP2 of petunia (Angenent et al., 1992), in spite of the very low degree of homology at the amino acid level. However, TM5 and FBP2 are not expressed in indeterminate vegetative shoot meristems (Pnueli et al., 1991; Angenent et al., 1992). By contrast, expression of TobMADS1, a ubiquitously expressed MADS-box gene in tobacco is detectable in both floral and vegetative organs of the tobacco plant (Mandel et al., 1994). Similar results have been reported for AGL3 of Arabidopsis (Huang et al., 1995) and TM3 of tomato (Pnueli et al., 1991). However, unlike PnMADS1, TobMADS1, AGL3 and TM3 mRNAs are detectable in all organs of the respective plants. StMADS16 and StMADS11 are structurally similar to PnMADS1 but their patterns of expression are completely different. StMADS16 and StMADS11 are expressed in all vegetative organs of potato plants, but not in floral tissues. There are no reported data on the expression of $A G L 24$, to our knowledge. Thus, PnMADS1 might be a novel MADS-box gene that is expressed specifically in shoot meristems and that contributes to the developmental program in both vegetative and reproductive organogenesis.

\section{Acknowledgements}

The authors thank Dr. J. Imamura for the gift of a genomic clone of $A G$, Dr. M. Hasebe for initial phylogenetic analysis and Dr. K. Nakahara for the phylogenetic analysis. This work was supported in part by a Grant-in-Aid for Scientific Research on Priority Areas (no. 07281101; Genetic Dissection of Sexual Differentiation and Pollination Processes in Higher Plants) from the Ministry of Education, Science, Culture and Sports, Japan, and by a Grantin-Aid for the "Research for the Future" Program (JSPS-RFTF97L00601) from the Japan Society for the Promotion of Science.

\section{References}

Altschul, S.F., Madden, T.L., Schaffer, A.A., Zhang, J., Zhang, Z., Miller, W., Lipman, D.J., 1997. Gapped BLAST and PSI-BLAST: a new generation of protein database search programs. Nucleic Acids Res., 25:
$3389-3402$.

Angenent, G.C., Busscher, M., Franken, J., Mol, J.N.M., Van Tunen, A.J., 1992. Differential expression of two MADS-box genes in wild-type and mutant petunia flowers. Plant Cell., 4: 983-993.

Aviv, H., Leder, P., 1972. Purification of biologically active globin messenger RNA by chromatography on oligothymidylic acid cellulose. Proc. Natl. Acad. Sci. USA, 69: 1408-1412.

Carmona, M.J., Ortega, N., Garcia-Maroto, F., 1998. Isolation and molecular characterization of a new vegetative MADS-box gene from Solanum tuberosum L. Planta, 207: $181-188$.

Coen, E.S., Meyerowitz, E.M., 1991. The war of the whorls: Genetic interactions controlling flower development. Nature., 353: 31- 37.

Frohman, M.A., Duch, M.K., Matin, G.R., 1998. Rapid production of full-length cDNAs from rare transcripts: amplification using a single gene-specific oligonucleotide primer. Proc. Natl. Acad. Sci. USA, 85: 89989002.

Hasebe, M., Wen, C.-K., Kato, M., Banks, J.A., 1998. Characterization of MADS homeotic genes in the fern Ceratopteris richardii. Proc. Natl. Acad. Sci. USA, 98: 6222- 6227.

Heard, J., Dunn, K., 1995. Symbiotic induction of a MADS box gene during development of alfalfa root nodules. Proc. Natl. Acad. Sci. USA, 92: 5273-5277.

Huang, H., Tudor, M., Weiss, C.A., Hu, Y., Ma, H., 1995. The Arabidopsis MADS-box gene AGL3 is widely expressed and encodes a sequence-specific DNAbinding protein. Plant Mol. Biol., 28: 549-567.

Imamura, S., 1967. Photoperiodic induction and the floral stimulus. In: Imamura, S. (Ed.): Physiology of Flowering in Pharbitis nil, 15-28. Japanese Society of Plant Physiologists, Tokyo.

Ma, H., Yanofsky, M.F., Meyerowitz, E.M., 1991. AGL1AGL6, an Arabidopsis gene family with similarity to floral homeotic and transcription factor genes. Genes and Dev., 5: 484- 495.

Mandel, T., Lutziger, I., Kuhlemeier, C., 1994. A ubiquitously expressed MADS-box gene from Nicotiana tabacum. Plant Mol. Biol., 25: 319-321.

Ozeki, Y., Matsui, K., Sakuta, M., Ohashi, Y., KanoMurakami, Y., Yamamoto, N., Tanaka, Y., 1990. Differential regulation of phenylalanine ammonia-lyase genes during anthocyanin synthesis and by transfer effect in carrot cell suspension cultures. Physiol. Planta., 80: 379-387.

Pearson, W.R., Lipman, D.J., 1988. Improved tools for biological sequence comparison. Proc. Natl. Acad. Sci. USA, 85: $2444-2448$.

Perry, S.E., Nichols, K.W., Fernandez, D.E., 1996. The MADS domain protein AGL15 localizes to the nucleus during early stages of seed development. Plant Cell., 8: $1977-1989$.

Pnueli, L., Abu-Abeid, M., Zamir, D., Nacken, W., Schwarz-Sommer, Z., Lifschitz, E., 1991. The MADS -box gene family in tomato: Temporal expression 
during floral development, conserved secondary structures and homology with homeotic genes from Antirrhinum and Arabidopsis. Plant J., 1: 255-266.

Purugganan, M.D., Rounsley, S.D., Schmidt, R.J., Yanofsky, M.F., 1995. Molecular evolution of flower development: Diversification of the plant MADS-box regulatory gene family. Genetics., 140: 345-356.

Rogers, S.O., Bendich, A.J., 1985. Extraction of DNA from milligram amounts of fresh, herbarium and mummified plant tissues. Plant Mol. Biol., 5: 69-76.

Rounsley, S., Ditta, G.S., Yanofsky, M.F., 1995. Diverse roles for MADS-box genes in Arabidopsis development. Plant Cell., 7: 1259-1269.

Sage-Ono, K., Ono, M., Harada, H., Kamada, H., 1998. Accumulation of a clock-regulated transcript during flower-inductive darkness in Pharbitis nil. Plant Physiol., 116: 1479-1485.

Saitou, N., Nei, M., 1987. The neighbor-joining method: a new method for reconstructing phylogenetic trees. Mol. Biol. Evol., 4: 406-425.

Schwarz-Sommer, Z., Huijser, P., Nacken, W., Saedler, H., Sommer, H., 1990. Genetic control of flower development by homeotic genes in Antirrhinum majus. Science., 250: $931-936$.

Shore, P., Sharrocks, A.D., 1995. The MADS-box family of transcription factors. Eur. J. Biochem., 229: 1- 13.
Thompson, J.D., Gibson, T.J., Plewniak, F., Jeanmougin, F., Higgins, D.G., 1997. The Clustal X windows interface: flexible strategies for multiple sequence alignment aides by quality analysis tools. Nucleic Acids Res., 24: 4876-4882.

Vince-Prue, D., Gressel, J., 1985. Pharbitis nil. In: Halevy, A. (Ed.): Handbook of Flowering, 47-81. CRC Press, Boca Raton.

Winter, K.-U., Becker, A. Munster, T. Kim, J.T., Saedler, H., Theissen, G., 1999. MADS-box genes reveal that gnetophytes are more closely related to conifers than to flowering plants. Proc. Natl. Acad. Sci. USA, 96: 7342 $-7347$.

Yanofsky, M.F., 1995. Floral meristems to floral organs: Genes and controlling early events in Arabidopsis flower development. Annu. Rev. Plant Physiol. Plant Mol. Biol., 46: 167-188.

Yanofsky, M.F., Ma, H., Bowman, J.L., Drews, G.N., Feldmann, K.A., Meyerowitz, E.M., 1990. The protein encoded by the Arabidopsis homeotic gene agamous resembles transcription factors. Nature., 346: 35-39.

Zachgo, S., Saedler, H., Schwarz-Sommer, Z., 1997. Pollen - specific expression of DEFH125, a MADS - box transcription factor in Antirrhinum with unusual features. Plant Cell., 11: 1043-1050. 